\title{
Effect of number of uses on the cyclic fatigue resistance of single-file rotary instruments
}

\author{
๑D Burçin Arıcan, (1)Ayfer Atav Ateş \\ İstanbul Okan University, Faculty of Dentistry, Department of Endodontics, İstanbul, Turkey
}

Cite this article as: Arıcan B, Atav Ateş A. Effect of number of uses on the cyclic fatigue resistance of single-file rotary instruments. J Health Sci Med 2021; 4(2): 176-180.

\begin{abstract}
Aim: The purpose of this study was to evaluate and compare the cyclic fatigue resistance of two different single file nickeltitanium instruments -Reciproc blue (RB) and One Curve (OC)- used for single or in a certain number of times.

Material and Method: One Curve ( $\mathrm{n}=40)$ and Reciproc Blue $(\mathrm{n}=40)$ files were used in this study. The instruments were divided into two subgroups $(\mathrm{n}=20)$; those to be used for the first time $(\mathrm{N})$ and those that were previously used (U) only once in the clinic for the root canal treatment of one vital mandibular molar with three root canals. Cyclic fatigue testing of these instruments was performed in an artificial stainless-steel canal with $60^{\circ}$ curvature, $5 \mathrm{~mm}$ radius $1.5 \mathrm{~mm}$ width, and $3.0 \mathrm{~mm}$ depth. All the tested files were rotated/reciprocated under the continuous irrigation with distilled water at $37^{\circ} \mathrm{C}$ until fracture occurred. The time to failure (TTF) in seconds and the number of cycles to failure (NCF) were recorded. Data were statistically analyzed and the significance level was set at $\mathrm{p}<0.05$.

Results: A significant difference was observed among the four groups and between RB-N/RB-U, OC-N/OC-U, RB-N/OC-N, and RB-U/OC-U, regarding TTF and NCF values $(\mathrm{p}<0.05)$. Predicted time for $99 \%$ survival were RB-N $>$ RB- $\mathrm{U}>\mathrm{OC}-\mathrm{N}>\mathrm{OC}-\mathrm{U}$. The TTF value of RB is greater than OC in both the new instrument groups and the used instrument groups.

Conclusions: RB showed higher cyclic fatigue resistance than OC files in both new and used instrument groups. Reuse of RB and $\mathrm{OC}$ instruments significantly reduced the cyclic fatigue resistance of the instrument.
\end{abstract}

Keywords: Cyclic fatigue, nickel-titanium, one curve, reciproc blue, single file

\section{INTRODUCTION}

Despite all technological advances in endodontics, file separation is still a vexing problem for dentists. Torsional failure and cyclic fatigue (flexural fatigue) are the two main causes of file separation. If the tip of the instrument stuck in the root canals but the coronal segment continues to rotate, torsional failure occurs (1). Besides, repeated cycles of tension and compression of the metal cause metal fatigue and thereby give rise to cyclic fatigue (2). The features of rotary instruments (such as kinematic, alloy type or manufacturing process) $(3,4)$ and factors depending on usage pattern (such as autoclave process, irrigation solutions) $(1,5)$ can cause cyclic fatigue. The single-file systems introduced to the market in 2008 (6) broke new ground in the world of endodontics and minimized the risk of instrument breakage as well as saving time, preventing cross-contamination and being cost-effective (7).

Recirpoc blue (RB) (VDW, GmbH, Munich, Germany) is a thermally treated single file nickel-titanium (NiTi) instrument. It works in the principles of reciprocation with unequal forward and reverse rotation which was reported as a unique feature that can reduce the incidence of file separation $(5,8)$. It can be used in both instrumentation and retreatment of the root canals. The file has a non-cutting tip with a S-shaped cross section and variable taper. According to the manufacturer's instructions, it can be used without any prior instrumentation or glide path creation (9).

One Curve (Micro Mega, Besançon, France) (OC) was introduced as the evolution of One Shape and was released in the market as a single file rotary instrument in 2018 by MicroMega. OC has improved mechanical properties thanks to its novel proprietary C-Wire heat-treatment controlled memory of NiTi (10). It has variable crosssections with a triangular-shaped at the tip and S-shaped near the shaft which enhances its cutting efficiency and centering ability (10). 
Although there are several in vitro studies in the literature that assess the influence of heat-treatment procedure, autoclave process, irrigation solutions and design of the single file rotary systems on the cyclic fatigue resistance, there is not any study that evaluates the cyclic fatigue resistance of the single-file systems that were either never used or used in a certain number of times in clinic, yet. For this reason, the purpose of this study was to evaluate and compare the cyclic fatigue resistance of new or were previously used (U) only one time in the clinic for the root canal treatment of one vital mandibular molar with three root canals. The null hypothesis was that the cyclic fatigue resistance of $\mathrm{OC}$ and $\mathrm{RB}$ used for the first time is higher than the previously used ones in the clinic.

\section{MATERIAL AND METHOD}

The authors declare that this study does not carry the qualification of experiments on humans and animals, biological materials (biological fluids such as blood, urine, extracted human teeth and tissue samples, etc.) and the present study was conducted in accordance with the principles of the Declaration of Helsinki.

Forty One Curve (25/.06) and 40 Reciproc Blue (25/.08) which were either new or used previously in certain times were used for the study. The summary of the group contents was as follows; New One Curve instruments (OC$\mathrm{N}$ ), One Curve used in the clinic (OC-U), New Reciproc blue instruments $(\mathrm{RB}-\mathrm{N})$, and Reciproc blue used in the clinic (RB-U).

\section{Backstage of New Instruments}

All the new files (20 OC-N/20 RB-N) were inspected at $40 \times$ magnification under a surgical microscope (Leica M320, Leica microsystems, Wetzlar, Germany). If any defect or deformity was observed, replaced it with a new one. No imperfect instrument was detected.

\section{Backstage of Used Instruments}

For multiple use groups (20 OC-U/20 RB-U), the files were selected from the pool of the used files which were classified and stored according to the cases in the clinic. These instruments were inspected at $40 \times$ magnification under a surgical microscope before use. Those selected instruments where the ones which were used only once in the treatment of a vital mandibular molar with three root canals in the clinic. The instruments which were used in the treatment of four root canals, calcified root canals, open apices, the teeth with a strongly curved root, maxillary molars or teeth with necrotic pulp were excluded from the study. All the root canal instrumentation was performed by a single operator.
In OC- $\mathrm{N}$ group, the apical patency of the teeth was checked with \#10 K file and the working length (WL) was determined with an apex locator. It was also checked with a periapical radiograph. The glide path was created with One $\mathrm{G}$ (300 rpm and $1.2 \mathrm{~N} / \mathrm{cm}$ torque) according to the manufacturer's instructions. OC was used in the root canals with back-and-forth motion without any apical pressure. If any resistance was experienced, the file was removed. The flutes were cleaned and the root canal was irrigated with $2 \mathrm{~mL} \mathrm{5.25 \%}$ sodium hypochlorite. This procedure was repeated until reaching the WL.

In RB-N group, the apical patency was checked with \#10 K file. WL was determined with an apex locator and checked with a periapical radiograph. The glide path was created by R-Pilot with original VDW Reciproc settings. The irrigant was placed to access the cavity and then $\mathrm{RB}$ was gently used in the canal with in-and-out pecking motion. After 3 pecking motions or any resistance was encountered, the instrument was removed from the canal and the debris on the flutes was cleaned with a sponge. The root canal was irrigated and this procedure repeated until reaching the WL.

The root canals were irrigated with $2 \mathrm{~mL}$ sodium hypochlorite $(\mathrm{NaOCl})$ after every withdrawal of instruments and after the completion of root canal instrumentation. All the teeth were obturated with $\mathrm{AH}$ Plus and gutta-percha using cold lateral condensation. The temporary crown restoration was done with glass ionomer cement. If there was a visible deformation of the instrument after use in a clinical case, it was discarded from the study.

Before sterilization, the debris on the used instruments was cleaned with an alcohol sponge and then files were rinsed with distilled water. The instruments were packaged singularly and subjected to 1 cycle of autoclave sterilization at the temperature of $134^{\circ} \mathrm{C}$ for 17 minutes (11). Before performing the cyclic fatigue test, the autoclaved files were allowed to cool at room temperature (5).

\section{Cyclic Fatigue Test}

The artificial stainless-steel canal with $60^{\circ}$ curvature, $5 \mathrm{~mm}$ radius, $1.5 \mathrm{~mm}$ width and $3.0 \mathrm{~mm}$ depth was used for the study. All the files were operated with a torquecontrolled endodontic motor (X-smart Plus, Dentsply Maillefer, Switzerland) following the recommendations of the manufacturers; Reciproc Blue in "Reciproc ALL" mode (Note: The manufacturers claim that the Reciproc modehas $300 \mathrm{rpm}$ ) and One Curve with $350 \mathrm{rpm}, 1.5 \mathrm{~N} / \mathrm{cm}$ torque. After the sterilization of the instruments in RB-U group, the expanded ring on the file was removed as explained in the previous study (12). To both mimic the clinical conditions and minimize the friction between the files and the steel, $37^{\circ} \mathrm{C}$ distilled water with continuous irrigation was used. The files were freely rotated/reciprocated in the 
static mode without any pecking motion until the fracture occurred. All the cyclic fatigue test steps were done by a second operator. The time to failure (TTF) was recorded in seconds by a chronometer both visually and audibly. The number of cycles to failure (NCF) for each instrument was calculated as follows; Time to fracture (in seconds) X The number of rotations or cycles/60 seconds.

\section{Statistical Analysis}

Data were analyzed with IBM SPSS Version 23. Conformity to normal distribution was examined using the Shapiro-Wilk test. One-way analysis of variance and Tamhane test for multiple comparisons were used to compare normally distributed NCF and TTF values according to the groups. Independent two sample t-test was used to compare normally distributed NCF and TTF values according to $\mathrm{OC}$ and $\mathrm{RB}$ instruments. Paired two sample t-test was used to compare NCF and TTF values according to time within groups. Evaluation of the variability of NCF and TTF between samples was performed by Weibull reliability analysis using Minitab 17 program. The significance level was set as $\mathrm{p}<0.05$.

\section{RESULTS}

Comparison of NCF and TTF values between and within the groups are presented in Table 1. A significant difference was observed among the four groups and between RB-N/RB-U, OC-N/OC-U, RB-N/OC-N, and RB-U/OC-U, regarding TTF and NCF values $(\mathrm{p}<0.05)$. However, no significant difference was observed between OC-N and RB-U ( $P>0.05)$. While RB-N had the highest mean values of NCF and TTF, OC-U had the worst results in these two parameters $(\mathrm{p}<0.05)$.
Weibull reliability plots with the probability of survival values for NCF and TTF are shown in Figure 1 and Figure 2 , and the related Weibull calculations (Weibull modulus, R2, predicted cycles, and time for $99 \%$ survival), mean values, and standard deviations are given in Table 2. According to Weibull calculations, around 1500 to 1750 rotations for RB-N, 1000 to 1250 for OC-N and RB-U, 750 to 1000 for OC-U were predicted at given speeds and $80 \%$ reliability. Predicted time for $99 \%$ survival were RB$\mathrm{N}>\mathrm{RB}-\mathrm{U}>\mathrm{OC}-\mathrm{N}>\mathrm{OC}-\mathrm{U}$. The TTF value of RB is greater than $\mathrm{OC}$ in both the new instrument groups and the used instrument groups.

\section{DISCUSSION}

While NiTi rotary instruments caused a revolution in endodontic therapy, it brought some concerns such as file separation. Considering the Pubmed literatures in the last decade, the finding of nearly 500 studies about instrument fractures and cyclic fatigue is the greatest proof of this situation. In a comprehensive literature review, there was no study evaluating cyclic fatigue resistance of $\mathrm{RB}$ and $\mathrm{OC}$ instruments that were either never used or used in certain times. Therefore, the aim of this was study was to evaluate the usage of these two single file instrument systems on CFR of the files. In the light of the findings, new instruments showed higher CFR than the used ones and so, the null hypothesis was accepted.

The main idea of single-use NiTi instruments is generally related to safety, workflow, and cross-contamination (13). Another drawback that creates this approach could be the autoclaving process and corrosion effect of $\mathrm{NaOCl}$ which is associated with file separation due to cyclic fatigue. However, there are studies in the

\begin{tabular}{|c|c|c|c|c|c|c|}
\hline & & \multicolumn{2}{|r|}{ RB } & \multicolumn{2}{|r|}{$\mathrm{OC}$} & \multirow[t]{2}{*}{$\mathbf{p}$} \\
\hline & & Mean \pm Sd & Median (min. - max.) & Mean \pm Sd & Median (min. - max.) & \\
\hline \multirow{3}{*}{ TTF } & New & $350.3 \pm 35.2$ & $342.3(301.7-408.7)$ & $239.3 \pm 39.2$ & $227.3(189.4-308.6)$ & $<0.001$ \\
\hline & Used & $248.5 \pm 24.7$ & $245.5(215.3-292.5)$ & $165.3 \pm 23.3$ & $165.5(123.3-205.5)$ & $<0.001$ \\
\hline & $\mathrm{p}$ & $<0.001$ & & $<0.001$ & & \\
\hline \multirow{3}{*}{ NCF } & New & $1751.7 \pm 175.8$ & $1711.3(1508.4-2043.4)$ & $1395.7 \pm 228.9$ & $1326.2(1104.9-1800.2)$ & $<0.001$ \\
\hline & Used & $1242.7 \pm 123.7$ & $1227.7(1076.7-1462.6)$ & $964.3 \pm 135.7$ & 965.7 (719.4 - 1198.6) & $<0.001$ \\
\hline & $\mathrm{p}$ & $<0.001$ & & $<0.001$ & & \\
\hline
\end{tabular}

\begin{tabular}{|c|c|c|c|c|c|c|c|c|}
\hline & $\mathbf{n}$ & $\begin{array}{l}\text { Speed } \\
(\mathrm{rpm})\end{array}$ & $\begin{array}{c}\text { NCF's } \\
\text { Mean } \pm \text { Sd }\end{array}$ & $\begin{array}{c}\text { TTF's } \\
\text { Mean } \pm \text { Sd }\end{array}$ & $\begin{array}{l}\text { Weibull } \\
\text { modulus }\end{array}$ & $\mathbf{R} 2$ & $\begin{array}{l}\text { Predicted cycles } \\
\text { for } 99 \% \text { survival }\end{array}$ & $\begin{array}{l}\text { Predicted time (s) } \\
\text { for } 99 \% \text { survival }\end{array}$ \\
\hline RB-N & 20 & 300 & $1751.7 \pm 175.8^{\mathrm{a}}$ & $350.3 \pm 35.2^{\mathrm{a}}$ & 12.6 & 0.88 & 1240 & 247.392 \\
\hline OC-N & 20 & 350 & $1395.7 \pm 228.9^{b}$ & $239.3 \pm 39.2^{\mathrm{b}}$ & 7.9 & 0.85 & 760 & 132.905 \\
\hline $\mathrm{RB}-\mathrm{U}$ & 20 & 300 & $1242.7 \pm 123.7^{b}$ & $248.5 \pm 24.7^{\mathrm{b}}$ & 12.4 & 0.9 & 840 & 181.971 \\
\hline $\mathrm{OC}-\mathrm{U}$ & 20 & 350 & $964.3 \pm 135.7^{c}$ & $165.3 \pm 23.3^{c}$ & 8.3 & 0.98 & 600 & 100.195 \\
\hline
\end{tabular}

Sd: Standard deviation, TTF: time to fracture, NCF: number of cycle to failure 
literature showing that extra heat treatment occurred during autoclave sterilization has a positive effect on the cyclic fatigue resistance of the rotary files $(14,15)$. In the present study, the used instruments were exposed to both extra heat due to autoclaving process and sodium hypochlorite during the shaping procedures. The positive effect of the former and the negative effect of the latter on the cyclic fatigue resistance may neutralize each other's effect and may have caused lower NCF and TTF values in the RB-U and OC-U groups.

According to the results of the present study: 1-OC file showed lower cyclic fatigue resistance than $\mathrm{RB}$ in both used and new instruments groups; 2 - New RB and OC files had higher CFR than the used ones; 3 - Used $\mathrm{RB}$ instruments had statistically better CFR than the new OC files. Gündoğar and Ozyurek (14) reported a parallel result with the first results of the present study that the CFR of RB was statistically higher than OC instruments. The second results of this study were also comparable with Pirani et al. (16) who showed the deformation on the tip and a certain degree of surface wear on the multi used single-file reciprocating systems. On the other hand, the third results are not comparable because there is no study on this topic, yet. In the authors' opinion, some properties such as M-Wire heat-treated alloy, the thin blue titanium oxide layer (17), and the small austenite grains on the surface (18) of RB may improve its flexibility and cyclic fatigue resistance and caused the third result. Above all, the main difference between the two instruments that gave rise to this finding is the motion kinematic. RB works on the principle of clockwise and counterclockwise motion which makes continuously progress the file towards the apex and reduce the CFR caused by taper lock, tension, and compression $(12,16,19)$.

Today we know that separation of root canal instruments depends on several factors such as challenging root canal anatomy, size of the rotary file, tooth type, operator's experience, location of the canal, incorrect or excessive use of the files (20-22). These situations are tried to be imitated in all ex vivo studies. In our study, the tooth type in the used instrument groups was standardized as vital mandibular molars with three root canals. All the treatments were performed by a single experienced endodontist. The instruments had the same tip size but different tapers.

Although $\mathrm{NiTi}$ instruments started a new era in endodontics in the early 1990s, they have increased the cost for dentists. Only $6 \%$ of endodontists identified rotary instrument systems economically (23). A current study conducted in the USA showed that $74 \%$ of the endodontists reuse the NiTi rotary instruments (24). Another study showed that $25.6 \%$ of general dentists and $36.1 \%$ of endodontists used rotary tools up to 6-10 times and none of them mentioned single-use of these instruments (25). Patturaja et al. (23) indicated that $41.3 \%$ of endodontists used the files until a visible distortion was observed. When taking into consideration that most of the company launching the rotary instruments as disposable instruments, these results are quite dramatic. Since it is a disputable fact that clinicians want to provide the best healthcare to their patients, only economic reasons can explain this high reuse rate.

The reuse of engine-driven instruments has been the subject of studies in the literature $(12,20,26)$ (Wolcott, Vieira, Bueno). Wolcott et al. (26) conducted a clinical study about the separation incidence of Protaper (Dentsply Maillefer, Ballaigues, Switzerland) rotary instruments and announced that the fracture resistance of the Protaper instrument was the same for the first 4 uses. Vieira et al (20) reported that the Protaper rotary instrument can be safely used by an experienced endodontist up to eight molars without a file separation. Bueno et al. (12) used the WaveOne and Reciproc files three times each on 358 posterior teeth in the clinic and reported only three instrument fractures. Although such studies encourage clinicians to reuse engine-driven instruments, it should be kept in mind that the instrument damage is cumulative $(20,27)$. The mechanical properties and cutting efficiency of the instrument may also change due to multiple uses and sterilization procedures. Therefore, CFR is not the only factor that determines the number of instruments used.

\section{CONCLUSION}

Within the limitations of this in vitro study, the reuse of $\mathrm{RB}$ and $\mathrm{OC}$ instruments significantly reduced the cyclic fatigue resistance of the instrument. RB showed higher cyclic fatigue resistance than OC files in both new and used instrument groups. According to the results of this study, although RB seems safer to use a second time than OC, caution should be exercised in the second use of both devices in the clinic. The finding that the predicted cycles for the survival of RB-U to be similar to OC-N may pave the way to further studies.

\section{ETHICAL DECLARATIONS}

Ethics Committee Approval: The authors declare that this study does not carry the qualification of experiments on humans and animals, biological materials (biological fluids such as blood, urine, extracted human teeth and tissue samples, etc.), observational and descriptive research without intervention (questionnaire, scale file scans, system model development, audio and video recordings) and does not require ethics committee approval. 
Informed Consent: For this type of study, formal consent is not required.

Referee Evaluation Process: Externally peer-reviewed.

Conflict of Interest Statement: The authors have no conflicts of interest to declare.

Financial Disclosure: The authors declared that this study has received no financial support.

Author Contributions: All of the authors declare that they have all participated in the design, execution, and analysis of the paper, and that they have approved the final version.

Acknowledgments: The authors thank VDW and MicroMega for providing instruments.

\section{REFERENCES}

1. Uslu G, Özyürek T, Yılmaz K, Plotino G. Effect of dynamic immersion in sodium hypochlorite and EDTA solutions on cyclic fatigue resistance of WaveOne and WaveOne gold reciprocating nickel-titanium Files. J Endod 2018; 44: 834-7.

2. Ayfer A, ARICAN B. Effects of sodium hypochloride on cyclic fatigue resistance of Biorace rotary instrument with different tip sizes. Atatürk Üniversitesi Diş Hekimliği Fakültesi Derg 2020; 20: 594-8.

3. Capar ID, Ertas H, Arslan H. Comparison of cyclic fatigue resistance of novel nickel-titanium rotary instruments. Aust Endod J 2015; 41: 24-8.

4. Pedullà E, Grande NM, Plotino G, Gambarini G, Rapisarda E. Influence of continuous or reciprocating motion on cyclic fatigue resistance of 4 different nickel-titanium rotary instruments. J Endod 2013; 39: 258-61.

5. Pedullà E, Benites A, La Rosa GM, et al. Cyclic fatigue resistance of heat-treated nickel-titanium instruments after immersion in sodium hypochlorite and/or sterilization. J Endod 2018; 44: 648-53.

6. Yared G. Canal preparation using only one Ni-Ti rotary instrument: preliminary observations. Int Endod J 2008; 41: 339-44.

7. Smith A, McHugh S, Bagg J. A study of visual and blood contamination on reprocessed endodontic files from general dental practice. Br Dent J 2005; 199: 522-5.

8. Plotino G, Grande N, Porciani P. Deformation and fracture incidence of R eciproc instruments: a clinical evaluation. Int Endod J 2015; 48: 199-205.

9. VDW Brochure. Accessed at 15 December 2020. Available at: https: //www.vdw-dental.com/fileadmin/Dokumente/Sortiment/ Aufbereitung/Reziproke-Aufbereitung/RECIPROC-blue/VDWDental-RECIPROCblue-User-Brochure-EN.pdf.

10. One Curve Brochure. Accessed at 29 December 2020. Available at: https: //micro-mega.com/wp-content/uploads/2020/2011/ 60301900-A_Flyer-One-Curve-Portfolio-EN_web.pdf.

11. Bulem ÜK, Kececi AD, Guldas HE. Experimental evaluation of cyclic fatigue resistance of four different nickel-titanium instruments after immersion in sodium hypochlorite and/or sterilization. J Appl Oral Sci 2013; 21: 505-10.

12. Bueno CSP, de Oliveira DP, Pelegrine RA, Fontana CE, Rocha DGP, da Silveira Bueno CE. Fracture incidence of WaveOne and Reciproc files during root canal preparation of up to 3 posterior teeth: a prospective clinical study. J Endod 2017; 43: 705-8.

13.VDW brochure, (https://www.vdw-dental.com/en/products/detail/ reciproc/). Accessed at 13 December 2020.

14.Gündoğar M, Özyürek T. Cyclic fatigue resistance of OneShape, HyFlex EDM, WaveOne Gold, and Reciproc Blue nickel-titanium instruments. J Endod 2017; 43: 1192-6.
15. Viana A, Gonzalez B, Buono V, Bahia M. Influence of sterilization on mechanical properties and fatigue resistance of nickel-titanium rotary endodontic instruments. Int Endod J 2006; 39: 709-15.

16. Pirani C, Paolucci A, Ruggeri O, et al. Wear and metallographic analysis of WaveOne and reciproc NiTi instruments before and after three uses in root canals. Scanning 2014; 36: 517-25.

17. De-Deus G, Silva EJNL, Vieira VTL, et al. Blue thermomechanical treatment optimizes fatigue resistance and flexibility of the Reciproc files. J Endod 2017; 43: 462-6.

18. Generali L, Puddu P, Borghi A, et al. Mechanical properties and metallurgical features of new and ex vivo used Reciproc Blue and Reciproc. Int Endod J 2020; 53: 250-64.

19. Plotino G, Grande N, Testarelli L, Gambarini G. Cyclic fatigue of Reciproc and WaveOne reciprocating instruments. Int Endod J 2012; 45: 614-8.

20. Vieira E, França E, Martins R, Buono V, Bahia M. Influence of multiple clinical use on fatigue resistance of ProTaper rotary nickeltitanium instruments. Int Endod J 2008; 41: 163-72.

21. Shen Y, Haapasalo M, Cheung GS-p, Peng B. Defects in nickeltitanium instruments after clinical use. Part 1: Relationship between observed imperfections and factors leading to such defects in a cohort study. J Endod 2009; 35: 129-32.

22. Wu J, Lei G, Yan M, Yu Y, Yu J, Zhang G. Instrument separation analysis of multi-used ProTaper Universal rotary system during root canal therapy. J Endod 2011; 37: 758-63.

23. Patturaja K, Leelavathi L, Jayalakshmi S. Choice of rotary instrument usage among endodontists-a questionnaire study. Biomed Pharmacol J 2018; 11: 851-7.

24.Logsdon J, Dunlap C, Arias A, Scott R, Peters OA. Current trends in use and reuse of nickel-titanium engine-driven instruments: a survey of endodontists in the United States. J Endod 2020; 46: 3916.

25. Mozayeni MA, Golshah A, Kerdar NN. A survey on NiTi rotary instruments usage by endodontists and general dentist in Tehran. Iran Endod J 2011; $6: 168$.

26. Wolcott S, Wolcott J, Ishley D, et al. Separation incidence of protaper rotary instruments: a large cohort clinical evaluation. J Endod 2006; 32: 1139-41.

27. Bahia MG, Buono VT. Decrease in the fatigue resistance of nickeltitanium rotary instruments after clinical use in curved root canals. Oral Surg Oral Med Oral Pathol Oral Radiol Endod 2005; 100: 24955 . 